Ida Malene Hartmann Rasmussen, cand mag. i Moderne kultur og kulturformidling, idamhr@gmail.com Bjarki Valtysson, lektor, Institut for Kunst og Kulturvidenskab, Københavns Universitet, valtysson@hum.ku.dk

\title{
At føle meget Affektive relationer i SKAM fanfællesskaber
}

\begin{abstract}
This article investigates SKAM's transmedia storytelling with specific focus on the affective relations between fans on the SKAM blog (http://skam.p3.no). Empirically, the article is based on data extracted from a focus group conducted with SKAM-fans and a qualitative content analysis of the communication found in the commentary section on the blog. Results indicate that SKAM's strategic use of transmedia storytelling is experienced by fans as authentic, and contributes to the emergence of affective online publics, where emotions and feelings run high.
\end{abstract}

Keywords: Fans, fællesskab, affektive relationer, tværmedialitet, SKAM-blog

\section{Introduktion}

Den norske ungdomsserie SKAM har fors $\varnothing$ gt at ramme de unge seere, ved at anvende de medier, som unge mennesker bruger i deres hverdag. Det gør SKAM til et interessant eksempel på moderne storytelling, hvor man ser indhold og struktur gå op i en højere enhed og hvor de forskellige mediers affordances flere gange om dagen bruges til at udvikle og udvide historien. Serien gør strategisk brug af digitale medier, hvor SKAM-bloggen (skam.p3.no) spiller en hovedrolle sammen med andre digitale udtryksformer som sociale medier (Instagram og Facebook) og SMS'er. Derudover står fansene også for en nærmest instrumental drift af det tværmediale historieunivers, da deres investering af tid og kræfter på bloggen skaber en ekstra dimension af affektive relationer, som binder fanfællesskabet sammen i bloggens kommentarspor.

SKAM's format skriver sig ind i former for deltagelseskulturer (Jenkins 2006), hvor fansene ikke regner med at tjene $\varnothing$ konomisk på deres deltagelse, da deres motivation snarere er at være aktive medskabere i en kultur, hvor kreativ udfoldelse, fællesskabsfølelse, samarbejde og selvpromovering er vigtige parametre (Gauntlett, 2011). De digitale teknologier gør dermed muligt for brugeren at engagere sig som et interaktivt publikum (Jenkins, 2006), hvor produsers (Bruns, 2008) ikke nøjes med at læse, men også at skrive (Lessig, 2008).

Denne artikel fokuserer primært på de affirmative dimensioner, der understreger de kreative potentialer fansene får afløb for gennem en produktion som SKAM. Artiklen lægger derfor vægt på fansenes deltagelse, udsagn og fascination i forhold til deres interesse i SKAM-universet. Det er dog vigtigt at understrege, at denne form for deltagelse og fascination altid er betinget af teknologien i et digitalt tværmedialt medielandskab, da den både faciliterer og begrænser de udtryksmuligheder, fansene har til rådighed. Den kommunikation der udfolder sig $\mathrm{i}$ SKAM-universet, er derfor påvirket af de muligheder som SKAM-bloggen, SMS'er og de sociale medier giver fansene i forhold til deres bevægelsesmuligheder som medskabere. 
Med andre ord påvirker teknologiens affordances fansenes "space of agency" (Sandvik, Thorhauge \& Valtysson, 2016) og omvendt. Dette er tydeligt, når man kigger nærmere på selve produktionen og distributionen af SKAM. Historien udvikler sig hovedsageligt på SKAM-bloggen, hvor de forskellige brudstykker af SKAM-livet samles. I stedet for at have et fast ugentligt afsnit, brydes afsnittet op i små bidder der udgives i realtid. Mellem de korte klip får man yderligere indblik i karakterernes liv gennem Instagrambilleder, SMS'er og Messenger-samtaler. Det gør, at fansene på daglig basis kan deltage og relatere til serien gennem de digitale medier de i forvejen bruger $\mathrm{i}$ deres eget digitale hverdagsliv. Denne produktionsmetode fører serien tættere på fansene og giver dem sammen med andre vigtige parametre en følelse af autenticitet, som fansene kan relatere til. Det er disse affektive relationer, der opstår blandt online og offline SKAM-fans, som er denne artikels hovedfokus. Med udgangspunkt i en fokusgruppe med danske SKAM-fans og en kvalitativ indholdsanalyse af kommentarsporet på SKAM-bloggen (skam.p3.no), vil vi i denne artikel undersøge de affektive relationer, der opstår blandt online og offline SKAMfans. Fokus vil derfor være på "cliffhanger-effekten", som seriens korte klip og opslag giver, den følelsesmæssige afhængighed, hvad der ligger i respondenternes italesættelse af sig selv som "SKAM-junkies", og SKAMfanfællesskabet.

\section{Metode og empiri}

Empirisk begrænser artiklen sig til den kommunikationstråd, der findes i SKAM-bloggens kommentarspor (http://skam.p3.no/ ) som er styret af NRK. SKAM-universet udfoldes også på andre fanfora og diverse kommercielle sociale medier, men da denne artikel søger at forstå effekten af de enkelte opslag og de affektive relationer opstået herefter, og da kommentarsporet netop afspejler den umiddelbare reaktion på et opslag, udelades de andre platforme. Der er et hav af faninteraktion på SKAM-bloggen, og til at begrænse mængden af data fokuserer vi især på den kommunikation, der udfoldede sig i forhold til 3. sæson af SKAM, efteråret 2016. Det var desuden med 3. sæson, at SKAM for alvor slog igennem på verdensplan, og derfor giver det god mening, at analysen tager sit afsæt her. Helt konkret drejer det sig om 135 opslag i den gældende periode. Hvert opslag har et sted mellem 50-1500 kommentarer. Grundet artiklens omfang, afgrænses det til de ca. 50 første kommentarer på hvert opslag, dvs. 6700 kommentarer. Til at organisere og kode dataene, anvender vi kvalitativ indholdsanalyse (Mayring, 2014), hvor man induktivt udvikler kategorier, som efterfølgende bliver deduktivt anvendt og udformet som bestemte temaer. De temaer som strukturerer artiklens analyse, er seriens produktionsstrategi og format, følelsesmæssig afhængighed og SKAM fanfællesskabet.

Udover den kvalitative indholdsanalyse af SKAM-bloggen gør vi også brug af en fokusgruppe (Halkier, 2008; Bloor, et al., 2001), da vi er interesserede i fansenes egne udtalelser og erfaringer med SKAM-fællesskabet. Fokusgruppen blev rekrutteret via eget netværk, og endte med at bestå af fire kvinder i alderen 25 til 28 , som alle karakteriserer sig selv som fans. Fokusgruppen underst $\varnothing$ tter indholdsanalysen med dybdegående informationer om SKAM-fanfællesskabet, det følelsesmæssige engagement og formatets betydning med 'de daglige cliffhangers'. Både fokusgruppens deltagere og kommentatorerne fra SKAM-bloggen er blevet anonymiseret i analysen.

\section{Seriens format}

Tværmedial storytelling, transmedia storytelling, remediering, polymedia, cross-media. Betydningen og brugen af disse begreber varierer, men sammen har de tilfælles at beskrive, hvordan indhold bliver påvirket af de medier og mediestrategier, der transmitterer indholdet. De finere variationer er ikke så vigtige i forhold til artiklens kontekst, men snarere den pointe at indhold aldrig kan formidles af platforme uden at blive påvirket af platformenes teknologi og platformenes socioøkonomiske forhold. Som van Dijck (2013) påpeger, er platforme ikke 'intermediaries', men snarere 'mediators'. Platformene formidler derfor ikke kun sociale forhold og adfærd, men påvirker dem også. Dette kan tydeligt ses på SKAM-bloggen og i fansenes reaktion på de klip, som regelmæssigt bliver frigivet. Bloggen og klip kan dog ikke afskæres fra de andre platforme, f.eks. Instagram og Facebook, som tit indgår i den diskussion, der finder sted på bloggen: "Er helt på tuppa her assa! Først oppdager man at det er et kvarters klipp igjen, så poster Isak en story på Insta hvor de tilsynelatende er på Plaza?! Hjertet mitt tåler ikke det her ass. Skam, der føkker med oss så jævlig opp nå! Vet ikke hvor jeg skal gjøre av meg :-O” (02.12.2016). 
Ved at implementere flere medier i historiefortællingen bliver SKAM-universet udvidet, og de engagerede fans som er til stede på de forskellige platforme bliver belønnet med særlige indblik og detaljer i narrativet. Udover at 'Insta-stories' bruges som varslinger på, hvad der er i vente og til at give yderlige informationer, så underst $\varnothing$ tter disse ekstra narrative elementer de officielle klip, f.eks. når Isak gør forholdet mellem ham og Even officielt via et billede på Instagram: "Ååååååh! Det fineste bilde poste på Insta leeeenge. Dette er den lykkelige slutten jeg har venta på hela sesongen! <3 ALT ER LOVE >3" (16.12.2016).

SKAMs integrerede tværmedialitet gør, at fansene kommunikerer med hinanden og hjælper hinanden med at få merværdi ud af seeroplevelsen. Da SMS'er, Instagram og Facebook indgår i fansenes naturlige brug af medier, bidrager disse medier til at gøre serien og dens kommunikation autentisk, og historiens tværmedialitet ender med at afspejle en realtid, som fansene sameksisterer i. Den kommunikation der finder sted $\mathrm{i}$ bloggens kommentarspor, viser også fansenes kendskab til de forskellige mediers affordances og deres rolle $\mathrm{i}$ at skabe agency og identifikation i forhold til fansenes hverdagsvaner og kommunikation (Sandvik, Thorhauge \& Valtysson, 2016). Dette kan ses i følgende reaktion på en SMS mellem Isak og Even: "De meldingene som er 'random' er nesten de som er søtest. Når du egentlig ikke har noe fonuftigt å si, men at du likevel ønsker kontakt, så du sender noe meningsløst. Søtt" (25.10.2016).

Seriens udformning er til konstant diskussion på bloggen, hvilket afspejler sig i kommunikationen i form af metarefleksioner og spekulationer om handlingen. Ved sæsonstart er mange kommentarer præget af en form for utålmodighed som bygger på de enorme forventninger, fansene har til serien: "Ikke mye spenning som bygger seg opp mot slutten her, gitt. Litt tynn historie denne sesongen? Lite som skjer, få klipp, ingen sidehistorier... sesong 1 og 2 skjedde jo litt med de andre karaktererne også. Begynner å bli litt kjedelig, ass..." (07.12.2016). Seriens format spiller derfor en ambivalent rolle hvor mange udtrykker frustration over de korte klip, hvilket vidner om, at fansene er bevidste om hvilken effekt formatet har på dem. Denne ambivalens kommer også til udtryk i fokusgruppen:

Altså, jeg synes det er meget ambivalent.. det er mega frustrerende, for man vil jo gerne have en update hver dag, men på samme måde, du får ikke rigtig tilfredsstillet det behov du egentlig har, fordi det typisk er mellem de her to til fire minutter.. men jeg har ikke mådehold til at sige: Godt, jeg venter til fredag. Også fordi det er en stor del af det, at se de her opdateringer, som ikke er klip. Dem der kun ser afsnit, tror jeg, går glip af nogle nuancer i det, for der er nogle ting, der ikke bliver nævnt i afsnittene, som giver en, en større forståelse af hele det her univers, når man ser alle de opdateringer der er... (Respondent 1)

Fansene arbejder konstruktivt med både deres afhængighed og utålmodighed over for konceptet, og omfavner ambivalensen ved disse frustrationer ved at hjælpe hinanden med at forstå seriens format og de begrænsninger, som den naturligt indeholder. De indgår frivilligt i seriens format, fordi den ikke kun giver dem ekstra indsigt $\mathrm{i}$ narrativet, men også samtidig styrker fanfællesskabet og den affektive relation til serien.

\section{I følelsernes vold}

Metarefleksionerne om seriens format understreger fansenes medieadfærd og behov. Fans, der i Jenkins' optik skal forstås som et interaktivt publikum, vil ikke længere nøjes med at stå passivt på sidelinjen, men insisterer derimod på at skulle have noget at sige og på retten til at deltage aktivt i deres egen kultur. Deres adfærd er derfor i takt med Lessigs (2008) og Gauntletts (2011) redegørelse for henholdsvis skrive/læse-kulturer og gøre/handle-kulturer. Alligevel må det forstås, at det også kan have emotionelle og sociale konsekvenser at navigere mellem forskellige medier, hvilket Madianou og Miller's (2012) koncept om polymedia angiver. Polymedia understreger den integrerede kultur, hvor hvert medie defineres relationelt i kontekst med andre medier, hvilket netop gør, at disse konsekvenser kan opstå. Dette mediebrug bliver tydeligt i den måde SKAMfansene relaterer både til universet som helhed, men også i den måde de italesætter deres brug og forståelse af de forskellige medier. Disse affektive aspekter glider for mange fans vedkommende fra utålmodighed og frustration over i en følelsesmæssig afhængighed - en decideret junkie-adfærd, som nogle fans selv påberåber 
sig i deres desperation. Men frem for at være skamfuld omkring denne voldsomme afhængighed, omfavnes det af fællesskabet, der sammen dyrker at være junkies.

Effekten af de korte klip som cliffhangere er et af de steder, hvor graden af SKAM-fans afhængighed bliver synlig: "Ja, det var akkurat det vi trengte etter den horrible slutten på dagens episode - en jævla pause. Kill me now, sier jeg bare. SKAM will be the end of me!" (05.11.2016). Da fansene er meget bevidste om narrativets og produktionens indbyggende suspense-effekt, har de svært ved at acceptere ventetiden mellem de forskellige klip. Mens de venter, florerer der på SKAM-bloggen livlig kommunikation: "4 timer siden, denne side er blevet opdateret, og fortsat absolut ingen livstegn. Men hvem tæller?! [...] Jeg klikker seriøst snart *click* (intet nyt) *click* (intet nyt) *click* (intet nyt) osv. (hjælp mig)" (07.12.2016). Denne desperation er typisk for den fællesskabsfølelse som eksisterer på bloggen, hvor der tilnærmelsesvis går konkurrence i at vise sin afhængighed af serien, mens det samtidig står klart, at de ikke er alene om disse stærke følelser: "Jeg bliver gal av å gå inn og oppdatere hele tiden..." (31.10.2016); som efterfølges af lang række kommentarer, der bekræfter denne form for følelser; "Ja, bliver helt dårlig av det her". Fiktionen glider ind i fansenes følelsesliv og medfører en stor indlevelse; noget som respondenterne også kommenterede i fokusgruppen:

Jeg tror aldrig at jeg har følt mig så involveret i en fiktiv persons liv, det er jo ekstremt, det dér real timeperspektiv, det er ekstremt medrivende, man føler sig også virkelig, sådan.. jeg sidder der og er 27 og boede i $\emptyset$ vrigt i Warszawa det sidste halve år, og følte mig nogle gange totalt latterlig, for jeg bare var sådan helt sådan: "NEEEEJ" (alle griner), hvor jeg nogen gange bare græd og sådan noget... men ja... Det er virkelig godt lavet. (Respondent 2)

Det er det vildeste jeg nogensinde har indlevet mig i, ligesom når man råber af en fodboldkamp, jeg er fodboldfan, når man råber af en fodboldkamp, det er fuldstændig den samme følelse af, - at hvis det her ikke sker nu, så dør jeg! (alle griner højt), og det havde vi så alle fire.. det var sindssygt. (Respondent 1)

Denne form for følelsesmæssig afhængighed er dybt forbundet med de teknologier, der fordrer kommunikationen, men også af det fremspirende kollektiv af fans på bloggen. Det er det boyd (2011) henviser til som networked publics; offentligheder restruktureret af teknologier, som konstruerer rum og grupper af mennesker. I SKAM's tilfælde er der dog ikke kun tale om networked publics, men networked affective publics. Dette indebærer, som Papacharissi (2015) påpeger, en bevidsthed om "det tredje sted": Online, uformelle mødesteder som er essentielle for dannelse og vedligeholdelse af fællesskaber, social kapital og civilt engagement. På SKAM-bloggen kommer det til udtryk i fansenes engagement og affektivitet over indholdet. På et diskursivt niveau relateres de til hinanden med et sprog, som på samme tid er eksistentielt og kropsligt. Fansenes engagement og identifikation siver ned i deres eget følelsesliv, som bliver forstærket via deres fælles bevidsthed som en networked affective public. "Åååå nå ble jeg nettopp sykt happy, og begynte å få tårer i Øynene, og hoppe opp og ned. Var så gira jeg ropte og klarte å velte vannglaset mitt da de blei avbrutt. Trodde aldi jeg skulle blive sint av å se Noora :( <3" (21.10.2016), og "Hvad er det SKAM gjør med meg?? Må bare si at det er helt vanvittig bra laga, spesielt denne sesongen. Jeg går rundt å føler meg nesten forelska i Even selv, og venter om det var meg han skal ta kontakt me. Det gjør vondt å vente vettu" (01.11.2016). Denne stærke affektive reaktion, når noget gør så ondt, og når man føler så meget, glider også ud i fysiske reaktioner: "Herregud jeg gråtter som en foss!" (09.12.2016), og "JEG FÅR IKKE PUSTE" (25.11.2016).

Denne følelsesmæssige afhængighed, hvilket nogle af fansene henviser til som SKAM-syken (stærk fysisk reaktion på serien såsom søvnløshed, mangel på appetit og tankemylder) er et samspil af mange parametre. Vi har diskuteret teknologiens rolle $\mathrm{i}$ at konstruere kommunikative rum, der $\mathrm{g} \varnothing \mathrm{r}$ at fansene overhovedet kan kommunikere. Men som boyd påpeger, konstruerer teknologier ikke kun rum (i dette tilfælde SKAM-bloggen), men også grupper af mennesker, hvilket i SKAM's tilfælde er bygget op af nogle bestemte karakteristika og normer. 


\section{Et SKAM-fanfællesskab}

Ifølge Jenkins (2006) bliver man først en reel fan, når man begynder at transformere det præsenterede indhold over på en kulturel aktivitet. Det gør man ved at dele følelser og tanker omkring programmets indhold med venner eller i fællesskaber, som deler samme interesse. I SKAM's tilfælde giver de digitale medier og bloggen fansene tilgængelige hverdagsteknologier til at kommunikere, men disse rum ville være tomme, hvis ikke fansene investerede affektivt i dem. Vi har allerede set eksempler på, hvordan fansene fremstår som fælles SKAM-hjerne, hvor praksis er baseret på en vis form for kollektivt vidensrum. Som Baym (2010) påpeger, kan fællesskaber beskrives ud fra sted, praksis (fællesskabet udvikler dets egen måde at kommunikere på), fælles medvirken til hinandens sociale kapital via støtte og deling af følelser, en vi-følelse og interpersonelle relationer.

Disse dynamikker gør sig gældende på bloggen, hvor fans engageres i diskussioner, som er af opklarende karakter: "Jeg glæder mig til at finde ud af mere om Isaks familie. Hvornår han ikke bor ved faderen? Har faderen fåt en ny familie? Hvorfor har han ikke snakket med moderen? Hvor meget ved Jonas og de andre?" (22.10.2016), som bliver besvaret med en opklaring fra fællesskabet. Andre diskussioner tager udgangspunkt i en personlig forståelse og analyse af karaktererne: "Jeg likte Isak veldig godt før, men han er jo ikke noe hyggelig i det hele tatt??! Hva skjer $\odot$ " (05.10.2016). Hvilket forsvares af en anden bruger: "Tror Isak har en tid der han har vanskeligheter med å vite hva han selv føler, ikke virker det som han skjønner det selv engang, kjenner meg igjen selv (-)".

Det bliver derfor til en form for fanpraksis, hvor de står sammen om at få den fulde forståelse af serien, og hvor dybere analyser bifaldes i fællesskabet: "Dæven du må være intelligent. Skjer med å greie å trekke sånne kompliserte tråde a? Jeg mener det" (26.10.2016). Der går også lidt sport i at spore de små gåder og hemmeligheder i mange af opslagene. Udover disse kommentarer som fællesskabet deler omkring seriens handling og symbolik, bliver der ofte diskuteret de bredere emner og tematikker som serien tager op, som biologi, homoseksualitet og evolution.

Det er dog de mere affektive emner, der giver størst dynamik på bloggen, f.eks. når Isak og Even kigger på hinanden når de endelig kysser for første gang: " $<3<3<3$ Dette er det fineste eg har sett" (28.10.2016) og "Jeg har aldrig blitt så glad for en episode før <3". Generelt set står SKAM-fansene, som de fremstår på bloggen, sammen som en enhed og de er bevidste om at fællesskabet føler og længes efter det samme. Vigtigheden af at kunne dele sine følelser med nogen kommer også klart til udtryk i fokusgruppen:

Helt sikkert, ellers ville jeg føle mig totalt ensom og tror, at jeg ville være ved at blive sindssyg. Altså, som sagt, så tror jeg, at det kommer helt vild meget an på hvem jeg er sammen med, jeg har klart haft følelsen af, at i nogen grupper, at jeg har været for meget eller haft lyst til at snakke for meget om Skam (de andre griner), eller har lavet for mange skam-referencer og snakket lidt for norsk (de griner igen), men de andre venner jeg har, der har været ligeså hooked på det, jeg har da haft meget mere lyst til at snakke med dem, haha, i en lang periode. (Respondent 2)

Dette sammenhold og fornemmelsen af at være en del af en helhed bliver også omtalt på bloggen, hvor man bliver stolt og rørt over at tilhøre fællesskabet: "En ting er sikkert: SKAM-red får ihvertfall frem det BESTE i oss seere. Kanskje der er det som er meningen? Når jeg leser igjennom (nesten) alle kommentarerne på hver episode-side o.l. bliver jeg STOLT og R $\emptyset \mathrm{RT}$ " (03.12.2016). Det er dog stadig væk de affektive relationer, som er de mest fremtrædende, hvor man får lov til at føle meget sammen med de andre fra fællesskabet: "NEEII FY SØREN DET ER IKKE SANT!???! HERREGUD. JEG GRÅTER NÅ. VAER SÅ SNILL. VEKK MEG FRA DENNE FORFERDERLIGE DRøMMEN" (01.12.2016). Kommentaren efterfølges af en masse støttende kommentarer og vidner derfor om, hvor vigtigt det er kunne føle meget og dele disse følelser med fællesskabet.

\section{Konklusion}

SKAM-universet figurerer i dens format som et socialt medie, hvis tekniske karakteristika styrer brugeren hen mod et forhøjet engagement og større indlevelse i universet (van Dijck, 2013). De daglige opslag formår at skabe 
en uforudsigelighed i narrativet og dertilhørende hungrende fans, idet cliffhangerne ender med at påvirke fansenes virkelighed og offentlighed. Den tværmediale historiefortælling griber altså ind i brugernes hverdag og følelsesliv på en uhyre effektiv facon. Formatet ender med at være fællesskabsskabende, idet de kan stå sammen omkring deres ambivalente forbrug af serien. Derfor lykkes SKAM som et tværmedialt univers, der både udnytter brugernes mediebrug og mediernes indbyggede affordances, men også brugernes deltagende adfærd og behov for at skabe fællesskaber omkring serien. Ved at være en aktiv del af kommentarsporet opnår brugerne merværdi og kan tage deres oplevelse med ud i den virkelige verden; alle handlingsmønstre der knytter sig til Jenkins ide om deltagelseskulturen. Selvom at de føler meget og hårdt, så står det klart, at fans godt kan lide denne form for følelsesmæssig involvering. SKAM-fans er i følelsernes vold og føler sig trygge nok i fællesskabet til at dele deres følelser. At føle meget er derfor en essentiel del af SKAM-universet; at føle med fællesskabet, at føle med karaktererne, at føle med skuespillerne, at føle med temaerne og at føle med og igennem hinanden. Det er disse affektive relationer, faciliteret af den tværmediale fortællestil, som primært gør SKAM til den succes som den nu er.

\section{Referencer}

Baym, N. (2010). Personal connections in the digital age. Cambridge: Polity Press.

boyd, d. (2011). Social network sites as networked publics: Affordances, dynamics, and implications. In Z. Papacharissi (Ed.) A Networked self: Identity, community, and culture on social network sites (pp. 39-58). New York \& London: Routlegde.

Bloor, M., Frankland, J., Thomas, M. \& Robson, K. (2001). Focus groups in social research. London: Sage.

Bruns, A. (2008). Blogs, wikipedia, second life, and beyond: from production to produsage. New York: Peter Lang.

Gauntlett, D. (2011). Making is connecting: The social meaning of creativity, from DIY and knitting to YouTube and web 2.0. Cambridge: Polity Press.

Halkier, B. (2008). Fokusgrupper. 2. udgave. Frederiksberg: Forlaget Samfundslitteratur.

Jenkins, H. (2006). Fans, bloggers, and gamers: exploring participatory culture. New York \& London: New York University Press.

Lessig, L. (2008). Remix: making art and commerce thrive in the hybrid economy. New York: The Penguin Press.

Madianou, M. \& Miller, D. (2012). Polymedia: Towards a new theory of digital media in interpersonal communication. International Journal of Cultural Studies, 16(2), 169-187.

Mayring, P. (2014) Qualitative content analysis: theoretical foundation, basic procedures and software solution. Klagenfurt, 2014. Lokaliseret på http://nbn-resolving.de/urn:nbn:de:0168-ssoar-395173

Papacharissi, Z. (2015). Affective publics: Sentiment, technology, and politics. Oxford: Oxford University Press.

Sandvik, K., Thorhauge, A.M. \& Valtysson, B. (2016). Spaces of agency at the intersection between media technologies and everyday life. In K. Sandvik, A. M Thorhauge \& B. Valtysson (Eds.) The media and the mundane: Communication across media in everyday life (pp. 151-156). Gothenburg: NORDICOM.

Van Dijck, J. (2013). The culture of connectivity: A critical history of social media. Oxford: Oxford University Press. 